\title{
Additional Reviewers in 2005
}

The Editors-in-Chief of Multiagent and Grid Systems - An International Journal, Professor Dr. Huaglory Tianfield and Professor Dr. Rainer Unland would like to thank the following people for their valuable help with reviewing of manuscripts for the Journal during 2005.

- Bernhard Bauer, University of Augsburg, Germany.

- Peter Braun, Swinburne University of Technology, Australia.

- Andreas Doerr, Sun Microsystems, Germany.

- Wolfgang Gentzsch, MCNC Grid Computing and Networking Services, USA.

- Sushant Goel, University of Melbourne, Australia.

- Dimitrios Korentzelos, Glasgow Caledonian University, UK.

- Bhanu Prasad, Florida A \& M University, USA.

- Fethi Rabhi, University of New South Wales, Australia.

- Omer Rana, University of Cardiff, UK.

- Craig Thompson, University of Arkansas, USA.

- Christof Weinhardt, University of Karlsruhe, Germany.

- Jianshu Weng, Nanyang Technological University, Singapore.

- Floriano Zini, Instituto Trentino di Cultura, Italy. 